\title{
Child Neurology: Hereditary Folate Malabsorption
}

Akshata Huddar, MD, DM, Shwetha Chiplunkar, MBBS, PhD, Madhu Nagappa, MD, DM, Periyasamy Govindaraj, PhD, Sanjib Sinha, MD, DM, Arun B. Taly, MD, DM, and

Bindu Parayil Sankaran, MD, DM, FRACP, PhD

Neurology ${ }^{\circledR}$ 2021;97:40-43. doi:10.1212/WNL.0000000000012083

\section{Correspondence}

Dr. Sankaran

bindu.parayilsankaran@

health.nsw.gov.au
Hereditary folate malabsorption (HFM, congenital folate malabsorption; OMIM\#229050) is a rare, potentially treatable autosomal recessive disorder with multisystem involvement. ${ }^{1}$ It is caused by homozygous or compound heterozygous mutations in SLC46A1 resulting in loss of function of proton-coupled folate transporter (PCFT), ${ }^{2}$ required for intestinal absorption and transport of folate across choroid plexus. ${ }^{1,2}$ This leads to the deficiency of folate in serum and CSF, causing hematologic, immunologic, gastrointestinal, and neurologic manifestations. ${ }^{1}$ Neuroimaging shows intracranial calcification. ${ }^{3}$ Diagnosis is confirmed by impaired absorption of an oral folate load, low CSF folate concentration (even after correction of the serum folate concentration), or the identification of pathogenic variants in SLC46A1 on molecular genetic testing. ${ }^{1}$ We describe the clinical, imaging, biochemical, and genetic findings of a patient with HFM.

\section{Case Report}

A 2 years, 8 months old girl, the second child of consanguineous parents, from the south Indian state of Karnataka, was referred to our center for evaluation. She was born at term by normal delivery following an uneventful antenatal period with a birthweight of $3.5 \mathrm{~kg}$. The perinatal period was uneventful. At 4 months of age, she presented to a peripheral hospital with fever, diarrhea, poor feeding, lethargy, and seizure. Evaluation showed hemoglobin of $3.4 \mathrm{~g} / \mathrm{dL}$, leucocyte count $6.9 \times 10^{9} / \mathrm{L}$, and platelets $16 \times 10^{9} / \mathrm{L}$, suggesting pancytopenia. Bone marrow examination showed a megaloblastic picture. She received blood transfusion, antibiotics, and vitamin $B_{12}$ and folate supplements, with a diagnosis of sepsis with pancytopenia. Hematologic measures improved, but the patient continued to have repeated respiratory and gastrointestinal infections requiring intensive care unit admissions. Seizures became refractory to multiple antiseizure drugs at optimal dosages (phenytoin, levetiracetam, carbamazepine, topiramate, and clobazam). By 11 months of age, the patient had generalized hyperpigmentation, tremors, and oral ulcers. Developmental delay was noted at 18 months of age, with episodes of further regression following infections. The diagnosis of infantile tremor syndrome, a nutritional deficiency syndrome typically associated with vitamin $B_{12}$ deficiency, characterized by pallor, developmental delay/regression, tremors, skin pigmentation, and brown scanty scalp hair, ${ }^{4}$ was considered at this stage. The patient received $B_{12}$ supplementation. At 32 months of age, she was able to sit and stand with support, transfer objects, and say 2-3 meaningful words. There was a history of similar illness in her older sister, with seizures, fever, vomiting, loose stools, and pancytopenia, who died at 3 months of age.

Examination revealed microcephaly (head circumference $45 \mathrm{~cm},<3 \mathrm{rd}$ percentile) and low weight (10.5 kg, <3rd percentile). The patient was alert, fixed, and followed light and sound. She had normal extraocular, facial, palatal, and tongue movements. She had generalized hypotonia, normal limb movements, and brisk deep tendon reflexes. She had choreoathetosis

From the Department of Neurology (A.H., S.S.) and Department of Clinical Neurosciences \& Neuromuscular Lab (S.C., M.B.B.S., P.D.) and Department of Neurology \& Neuromuscular Lab (M.N., A.B.T.), Neurobiology Research Centre, the National Institute of Mental Health and Neuro-Sciences (NIMHANS); Institute of Bioinformatics (P.G.), Manipal Academy of Higher Education, Bangalore, India; and The Children Hospital at Westmead Clinical School (B.P.S.), Sydney Medical School, The Faculty of Medicine and Health, The University of Sydney, Australia.

Go to Neurology.org/N for full disclosures. Funding information and disclosures deemed relevant by the authors, if any, are provided at the end of the article. 

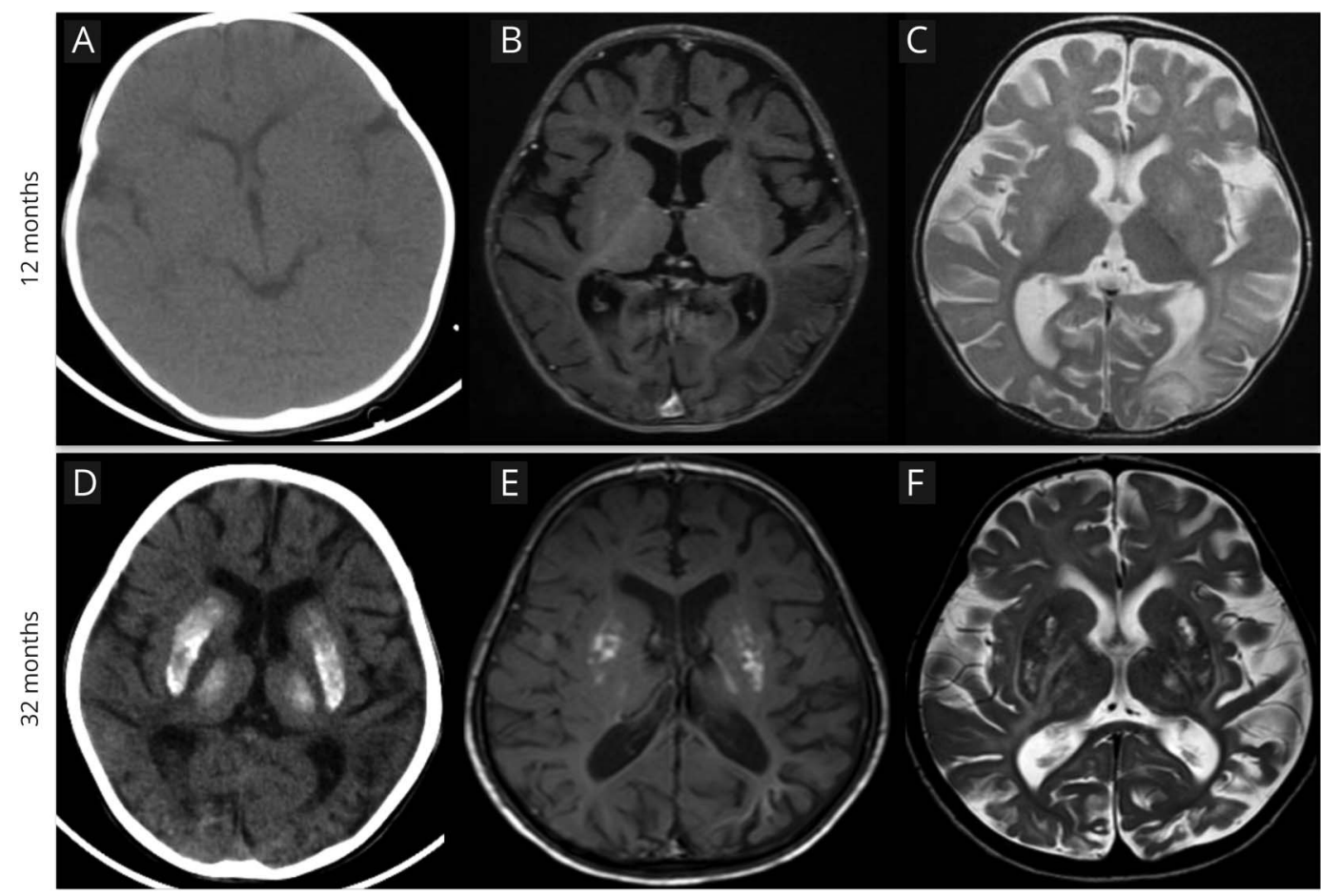

(A) CT scan at 1 year of age shows no evidence of basal ganglia calcification. (B, C) Brain MRI 1 month later. T1-weighted axial view (B) shows cerebral atrophy and hypointensity involving left temporo-occipital region. T2-weighted axial view (C) shows cerebral atrophy, basal ganglia signal changes, and left sided parieto-occipital hyperintensity. (D-F) Neuroimaging at 2 years and 8 months. (D) CT brain demonstrates bilateral basal ganglia and thalamic and parietooccipital calcification. (E) MRI brain T1-weighted axial sections show cerebral and cerebellar atrophy and patches of hyperintensity. (F) MRI brain T2weighted axial image shows mixed intensity signal changes in basal ganglia, thalamus, and white matter.

involving distal extremities. There was no organomegaly. Fundus showed normal retina and optic discs.

Investigations revealed anemia (hemoglobin $10.4 \mathrm{~g} / \mathrm{dL}$, reference $13-17 \mathrm{~g} / \mathrm{dL}$ ) with mean corpuscular volume on higher end of normal (96.6 fL, reference 83-101 fL) and normal leukocyte and platelet count. Renal and hepatic function tests were normal. Serum folate $(1.52 \mathrm{ng} / \mathrm{mL}$, reference $3.1-19.9$ $\mathrm{ng} / \mathrm{mL})$ and vitamin $\mathrm{B}_{12}(54 \mathrm{pg} / \mathrm{mL}$, reference $180-914 \mathrm{pg} /$ $\mathrm{mL})$ were low, while homocysteine was high $(27.8 \mu \mathrm{mol} / \mathrm{L}$, reference $<8 \mu \mathrm{mol} / \mathrm{L})$. Metabolic investigations revealed normal lactate, mildly elevated ammonia, and normal plasma amino acids, acylcarnitine profile, and urinary organic acid profile.

Cranial CT scan done at 12 months of age (figure) was normal. MRI brain done at 13 months showed mild cerebral atrophy and hypointensity involving the basal ganglia and left parieto-occipital region on T1-weighted images (figure) with corresponding hyperintensity on T2-weighted sequences (figure). Repeat neuroimaging at 32 months of age showed progressive changes, including calcification in bilateral basal ganglia and thalamus on CT scan (figure). MRI brain done at 32 months showed diffuse cerebral and cerebellar atrophy, T2/fluid-attenuated inversion recovery hyperintensities of periventricular and deep white matter, and mixed intensity lesions in bilateral basal ganglia (figure). EEG showed focal epileptiform activity across the left temporal region.

Constellation of megaloblastic anemia, oral ulcers, recurrent infections, and neurologic features with positive family history and biochemical and imaging findings led to the suspicion of hereditary folate deficiency. CSF folate estimation was not done. Clinical exome sequencing showed a pathogenic homozygous single base pair duplication in exon 2 of the SLC46A1 (chr17:26732094_26732095dupC) c.620dupG variation resulting in a frameshift and premature truncation of the protein 25 amino acids downstream to codon 208 (p. Tyr208LeufsTer25; ENST00000440501), confirming the diagnosis of HFM. Both parents were heterozygous carriers.

The patient received oral folic acid from 4 months of age prior to presentation to our facility. Hematologic measures and hyperpigmentation improved, but neurologic features worsened, and she continued to have recurrent infections. After the genetic diagnosis, she was treated with intramuscular injection of folinic acid $(120 \mathrm{mg} / \mathrm{d})$, leading to the cessation of seizures. After 1 week, parenteral folinic acid was replaced by oral folinic acid (150 mg/d, $15 \mathrm{mg} / \mathrm{kg} / \mathrm{d})$ due to financial constraints and continued along with anticonvulsants. At 2 months follow-up, she was seizure-free, and development had stabilized. However, she was noncompliant with treatment 
and presented multiple times with recurrent seizures, anemia, and infections, which responded to parenteral folinic acid. On follow-up at 7 years, the patient was able to stand with support, speak 5-10 words, and feed herself. Although there was a reduction in seizure frequency, she continued to have daily seizures requiring multiple anticonvulsants.

\section{Discussion}

HFM was first described in 1961 in an infant with relapsing megaloblastic anemia. ${ }^{5}$ Patients with HFM are normal at birth as they have in utero stores of folate and develop symptoms within 2-6 months of age due to impaired absorption and transport of folate. ${ }^{1}$ Folates mediate many important biological processes. ${ }^{6}$ In HFM, there is both systemic and cerebral deficiency of folate and 5-MTHF (5-methylenetetrahydrofolate; the active form of folate), leading to multisystem involvement: (1) hematologic: megaloblastic anemia, pancytopenia; (2) immunologic: recurrent infections, stomatitis, failure to thrive, reduced immunoglobulins; (3) gastrointestinal: diarrhea, stomatitis, failure to thrive; and (4) neurologic: epilepsy, movement disorder, ataxia, peripheral neuropathy, acquired microcephaly with progressive encephalopathy. ${ }^{6}$ The neurologic manifestations could be part of the initial presentation or can appear later in the disease course.

Our patient presented with multisystem involvement. Her older sibling also had multisystem involvement with a severe phenotype and died undiagnosed without adequate health care at age 3 months. This illustrates the fatal outcome in the absence of appropriate treatment. Untreated, the intracranial changes are progressive, as depicted in our patient. Intracranial calcification involving the cortex and basal ganglia has been reported in HFM and can be prevented by folinic acid therapy. ${ }^{3,7}$ Therefore, children with neurologic manifestations and intracranial calcification should be evaluated for disorders of folate metabolism, including SLC46A1 mutations. ${ }^{8}$ Other reported imaging abnormalities include cerebral and cerebellar atrophy. ${ }^{3,7}$ The intracranial calcifications are not specific to HFM and can also be seen in other genetic diseases, including Aicardi-Goutières syndrome, RNASET2, collagen IV-related disorders, Cockayne syndrome, and other DNA repair disorders, among others. ${ }^{8}$

The biochemical markers of HFM include low levels of serum folate, immunoglobulins, and CSF 5-MTHF, high level of serum homocysteine, and failure to raise serum folate levels after oral folate load. ${ }^{1}$ The diagnosis is confirmed by the presence of biallelic pathogenic variants in SLC46A1, including nonsense, missense, frameshifts, and splice site variants. $^{2}$ There is no clear phenotype-genotype correlation. ${ }^{1}$ The Tyr208 residue is located in the highly conserved region of extracellular loop 3 of the PCFT, leading to an unstable protein or protein with reduced function.

The differential diagnoses of HFM include acquired folate and $\mathrm{B}_{12}$ deficiency due to nutritional and pharmacologic causes, immunodeficiency diseases, inborn errors of metabolism, mitochondrial disorders, and malignancy like erythroleukemia. ${ }^{1}$ Folate metabolism disorders present with either neurologic manifestations alone or a combination of both hematologic and neurologic features. ${ }^{6}$ Hematologic manifestations are seen in HFM (SLC46A1), 5,10-methylenetetrahydrofolate dehydrogenase deficiency (MTHFD1), and dihydrofolate reductase deficiency. ${ }^{6}$

Cerebral folate deficiency (CFD) is characterized by low CSF 5-MTHF levels but normal serum folate levels and is caused by loss of function mutations in folate receptor- $\alpha(F R \alpha) .{ }^{9}$ This is an autosomal recessive disorder and differs from HFM. Whereas HFM presents within a few months of birth, patients with CFD present later, with developmental delay/regression, ataxia, motor disorders, hypotonia, and seizures., 2,9

HFM is one of the few treatable inborn errors of metabolism. ${ }^{6}$ Oral or parenteral folinic acid/levofolinate leads to improved systemic features and serum folate levels over 1-2 months. CSF 5-MTHF levels remain low for a longer period of time even with higher doses, and there is a partial response concerning neurologic symptoms. ${ }^{7}$ Intramuscular folinic/ levofolinic acid in a dose of $1-2 \mathrm{mg} / \mathrm{kg} / \mathrm{d}$ has led to normalization of CSF levels by 9-12 months in few cases. ${ }^{7,10}$ Preventive treatment with intramuscular folinic acid has been reported in one patient with HFM whose older sibling had severe illness and treatment commenced on day 2 of life. The patient remained symptom-free until 6 months of age, at last follow-up. ${ }^{7}$ Oral folate should not be used as it competes with 5-MTHF for cerebral folate receptor and impairs transport across choroid plexus, resulting in worsening neurologic symptoms, as in our patient. ${ }^{10}$ Higher doses of folinic acid, parenteral in preference to oral folinic acid, early intervention, and compliance are required to achieve good neurologic outcome. ${ }^{7}$ Genetic counseling with prenatal/early screening of other siblings is also warranted. ${ }^{1}$

\section{Study Funding}

This study was supported by a grant from the Indian Council of Medical Research to Bindu Parayil Sankaran (grant 54/9/ 2012-HUM-BMS).

\section{Disclosure}

Dr. Huddar, Dr. Chiplunkar, Dr. Nagappa, Dr. Govindaraj, Dr. Sinha, and Dr. Taly report no disclosures. Dr. Sankaran reports receipt of a grant from the Indian Council of Medical Research (grant 54/9/2012-HUM-BMS). Go to Neurology. org/N for full disclosures.

\section{References}

1. Kronn D, Goldman ID. Hereditary folate malabsorption: 2008 June 17 (updated 2017 April 27). In: Adam MP, Ardinger HH, Pagon RA, et al, eds. GeneReviews ${ }^{\odot}$. University of Washington; 1993-2020.

2. Zhao R, Aluri S, Goldman ID. The proton-coupled folate transporter (PCFTSLC46A1) and the syndrome of systemic and cerebral folate deficiency of infancy: hereditary folate malabsorption. Mol Aspects Med 2017;53:57-72.

3. Ahmad I, Mukhtar G, Iqbal J, Ali SW. Hereditary folate malabsorption with extensive intracranial calcification. Indian Pediatr. 2015;52(1):67-68 
4. Goraya JS, Kaur S. Infantile tremor syndrome: a review and critical appraisal of its etiology. J Pediatr Neurosci. 2016;11(4):298-304.

5. Lubhy AL, Eagle FJ, Roth E, Cooperman JM. Relapsing megaloblastic anemia in an infant due to a specific defect in gastrointestinal absorption of folic acid. Am J Dis Child. 1961;102:482-483.

6. Scaglia F, Blau N. Disorders of folate metabolism and transport. In: Blau N, Duran M, Gibson KM, Dionisi-Vici C, eds. Physician's Guide to the Diagnosis, Treatment, and Follow-Up of Inherited Metabolic Diseases. Springer; 2014:167-178.

7. Manea E, Gissen P, Pope S, Heales SJ, Batzios S. Role of intramuscular levofolinate administration in the treatment of hereditary folate malabsorption: report of three cases. JMD Rep. 2018;39:7-12.
8. Tonduti D, Panteghini C, Pichiecchio A, et al. Encephalopathies with intracranial calcification in children: clinical and genetic characterization. Orphanet J Rare Dis. 2018;13(1):135.

9. Grapp M, Just IA, Linnankivi T, et al. Molecular characterization of folate receptor mutations delineates cerebral folate transport deficiency. Brain. 2012;135(pt 7): 2022-2031.

10. Lubout CMA, Goorden SMI, van den Hurk K, et al. Successful treatment of hereditary folate malabsorption with intramuscular folinic acid. Pediatr Neurol. 2020; 102:62-66.

\section{Online Learning for Everyone}

No matter your career stage, interest, or learning style, the AAN has a wide variety of convenient online CME, self-assessment, and other learning activities to suit your needs. From bite-sized learning opportunities to self-assessment programs, help preparing you for the boards or continuing certification, or on-demand access to popular AAN conferences, the AAN has you covered. Visit AAN.com/Learn today.

\section{Share Your Artistic Expressions in Neurology 'Visions'}

AAN members are urged to submit medically or scientifically related artistic images, such as photographs, photomicrographs, and paintings, to the "Visions" section of Neurology $y^{\bullet}$. These images are creative in nature, rather than the medically instructive images published in the NeuroImages section. The image or series of up to six images may be black and white or color and must fit into one published journal page. Accompanying description should be 100 words or less; the title should be a maximum of 96 characters including spaces and punctuation.

Please access the Author Center at NPub.org/authors for full submission information.

\section{Disputes \& Debates: Rapid Online Correspondence}

The editors encourage comments on recent articles through Disputes \& Debates:

Access an article at Neurology.org/ $\mathrm{N}$ and click on "MAKE COMMENT" beneath the article header.

Before submitting a comment to Disputes \& Debates, remember the following:

- Disputes \& Debates is restricted to comments about articles published in Neurology within 6 months of issue date

- Read previously posted comments; redundant comments will not be posted

- Your submission must be 200 words or less and have a maximum of 5 references; the first reference must be the article on which you are commenting

- You can include a maximum of 5 authors (including yourself) 


\section{Neurology}

\section{Child Neurology: Hereditary Folate Malabsorption}

Akshata Huddar, Shwetha Chiplunkar, Madhu Nagappa, et al.

Neurology 2021;97;40-43 Published Online before print April 23, 2021

DOI 10.1212/WNL.0000000000012083

\section{This information is current as of April 23, 2021}

\section{Updated Information \&} Services

\section{References}

Subspecialty Collections

Permissions \& Licensing

Reprints including high resolution figures, can be found at: http://n.neurology.org/content/97/1/40.full

This article cites 8 articles, 0 of which you can access for free at: http://n.neurology.org/content/97/1/40.full\#ref-list-1

This article, along with others on similar topics, appears in the following collection(s):

\section{All Genetics}

http://n.neurology.org/cgi/collection/all_genetics

CT

http://n.neurology.org/cgi/collection/ct

Metabolic disease (inherited)

http://n.neurology.org/cgi/collection/metabolic_disease_inherited MRI

http://n.neurology.org/cgi/collection/mri

Information about reproducing this article in parts (figures,tables) or in its entirety can be found online at:

http://www.neurology.org/about/about_the_journal\#permissions

Information about ordering reprints can be found online:

http://n.neurology.org/subscribers/advertise

Neurology ${ }^{\circledR}$ is the official journal of the American Academy of Neurology. Published continuously since 1951, it is now a weekly with 48 issues per year. Copyright () 2021 American Academy of Neurology. All rights reserved. Print ISSN: 0028-3878. Online ISSN: 1526-632X.

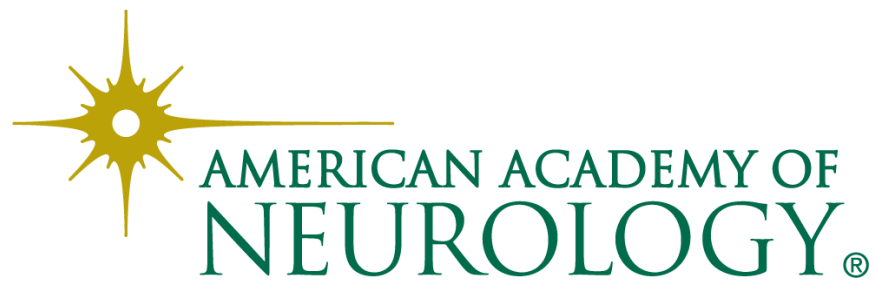

